\title{
The role of physiological and subjective measures of emotion regulation in predicting adolescent wellbeing
}

\author{
Lucy Morrish - Tan Chyuan Chin · Nikki Rikard · Peta Sigley-Taylor • Dianne Vella-Brodrick
}

\begin{abstract}
Emotion regulation (ER) is a key contributor to psychosocial adjustment in adolescence, while ER deficits contribute to psychological distress and dysfunction. To date, research with adolescents has examined a limited subset of ER processes, often in relation to mental ill-health. This study examined associations between multiple ER measures and wellbeing in a normative sample of 119 adolescents (Mage $=15.73$ ). ER was measured using self-report and physiological (RSA) indices. Multiple measures of positive and negative functioning were examined. After controlling for covariates, hierarchical regression analyses revealed that self-reported ER predicted resilience, perseverance, connectedness, and happiness; and fewer depression and anxiety symptoms. Higher tonic RSA predicted resilience and perseverance. Effect sizes were small to moderate. Theoretical and practical implications are discussed.
\end{abstract}

Keywords: adolescence, emotion regulation, respiratory sinus arrhythmia, mental health, positive youth development, resilience, wellbeing

\section{Introduction}

Adolescence is a period marked by vast emotional change, and the capacity for adaptive emotion regulation (ER) contributes to the successful transition into adulthood (Silk, Steinberg, \& Morris, 2003). During adolescence, the capacity to successfully regulate emotional experiences facilitates the building and maintenance of social relationships (Halligan et al., 2013), bolsters positive affect (Tugade \& Fredrickson, 2007), and promotes academic achievement (Ivcevic \& Brackett, 2014). Conversely, the absence of adaptive ER skills and the development of maladaptive ER strategies contribute to psychological distress and dysfunction (see meta-analytic reviews by Aldao, Nolen-Hoeksema, and Schweizer; Graziano \& Derefinko, 2013). ER can, therefore, be regarded as a key feature of positive youth development, and of the wellbeing spectrum more broadly (Keyes, 2005).

ER is defined as the ability to manage, modify, and respond to emotional experiences in a contextually appropriate manner (Thompson, 1994). A multidimensional construct, ER involves a variety of physiological, cognitive, and behavioral processes that emerge as particularly relevant during adolescence development (Steinberg, 2016). Mid-adolescence, for example, involves a developmental window characterized by maturational disparity between the prefrontal cortex and limbic system, leading to a period in which emotion- and rewarddriven behavior dominates rational decision making (Casey, Jones, \& Hare, 2008). ER is 
thought to be a prerequisite to effective impulse control, delayed gratification, and goaldirected behavior, and modulates emotion-driven urges (Davidson, Putnam, \& Larson, 2000; Ochsner \& Gross, 2005; Steinberg, 2016). Further, ER can buffer against the impact of early childhood experiences, biological and socio-cultural changes associated with puberty, and adverse environmental conditions on adolescent wellbeing (see Beauchaine 2015, for a review).

In contrast to the protective role of adaptive ER processes, ER disruption occurs when an individual's response to emotional arousal loses flexibility or is unresponsive to contextual demands (Cole, Martin, \& Dennis, 2004). Once a dysregulatory pattern is established, it becomes maladaptive and may sustain or promote mental ill-health (Berking \& Wupperman, 2012). As such, limited access to adaptive ER strategies and use of maladaptive strategies impairs wellbeing and contributes to the development of numerous forms of psychological distress and disorder (see meta-analytic reviews by Aldao et al., 2010; Graziano \& Derefinko, 2013). To date, the majority of ER research with young people has focused on its relation to psychological dysfunction. This is certainly warranted, given that adolescence is a period of risk for the onset of mental distress and ill-health, and deficits of ER represent a common feature of numerous mental disorders (Aldao et al., 2010). However, emerging theory suggests that processes of ER also contribute to positive psychological functioning in adolescent (Morrish, Rickard, Chin, \& Vella-Brodrick, 2018) and adult samples (Quoidbach, Mikolajczak, \& Gross, 2015), and despite these investigative inroads, empirical investigation of the role of ER to a broad range of measures of positive functioning in young people remains under explored. This represents a clear gap in our current understanding and fails to acknowledge the full spectrum of mental health, which includes distinct dimensions of positive and negative functioning (Westerhof \& Keyes, 2010).

\subsection{Emotion regulation and adolescent wellbeing}

Consistent with contemporary definitions of wellbeing as the combination of feeling good and functioning well (Huppert, 2009), wellbeing involves positive functioning across a range of biopsychosocial domains. The PERMA model (Seligman, 2011) identifies five interrelated facets, including Positive emotion, Engagement, positive Relationships, Meaning or purpose in life, and Accomplishment. In principle, the same ER processes that protect against the development of mental ill-health can also be utilized to promote positive psychological functioning, and PERMA specifically, in young people. To elaborate, adaptive ER involves harnessing one's physiological and cognitive resources in order to (i) select an appropriate strategy to influence one's affective experience and actions, and (ii) promote goal-attainment in emotionally charged situations (Gratz \& Roemer, 2004). These abilities become particularly important in the face of setbacks, challenges, or competing goals (Ivcevic \& Brackett, 2014). By engaging one's adaptive resources, processes of ER likely play a driving role in the realization and maintenance of psychological health (DeSteno, Gross, \& Kubzansky, 2013). For example, the use of adaptive cognitive ER strategies, including reappraisal, savoring, and gratitude, have all been found to enhance positive affect, while physiological measures linked to ER capacity (i.e., respiratory sinus arrhthymia) correlate with measures of trait positive affect and greater 
stability of positive affect in young adult samples (Fredrickson, Tugade, Waugh, \& Larkin, 2003; Koval et al., 2013; Oveis et al., 2009; Quoidbach, Berry, Hasenne, \& Mikolajczak, 2010; Tugade \& Fredrickson, 2007; Wang, Lü, \& Qin, 2013). Furthermore, in a sample of 210 undergraduate students (mean age $=21$ ), Gross and John (2003) found that reappraisal strategy use was positively associated six domains of wellbeing (Ryff \& Keyes, 1995), including environmental mastery, autonomy, personal growth, self-acceptance, and positive relations with others, as well as measures of optimism, self-esteem, and life satisfaction. Conversely, a putatively maladaptive cognitive ER strategy, expressive suppression, was inversely related to these domains. Such findings demonstrate a link between at least two specific ER strategies and wellbeing, however, there remains a clear need to move beyond "the usual suspects" of reappraisal and suppression, and extend current knowledge by considering the relationship of a more comprehensive range of ER capabilities to positive functioning (Gratz, Weiss, \& Tull, 2015).

\subsection{Emotion regulation: A mixed-model approach}

Given the multidimensional nature of ER, which involves both cognitive and physiological components, comprehensive assessment of its relationship to adolescent wellbeing requires a mixed-method approach (Beauchaine \& Thayer, 2015), which, in addition to self-report, includes physiological measures of neural and cardiovascular processes underlying ER (DeSteno, Gross, \& Kubzanski, 2013; Thayer, Åhs, Fredrikson, Sollers III, \& Wager, 2012). Typically, research with adolescent samples has involved only one method of measuring ER (Adrian, Zeman, \& Veits, 2011). This approach is problematic, as it limits cross-study comparisons and provides a partial understanding of the relationship of ER to mental health, and specifically, to positive aspects of psychological functioning that remain largely unexplored in mixed-method designs. Cognitive ER strategies, assessed via self-report, are most often represented in the literature and refer to the ways individuals think about their emotions to make sense of, manage, and respond appropriately to them (Garnefski, Kraaij, \& Spinhoven, 2001). However, physiological indices of ER - thought to reflect an individual's capacity to engage in adaptive ER processes (Thayer et al., 2012) - are increasingly examined, and involve changes in neurocognitive and autonomic nervous system functioning associated with emotional experience and regulation.

\subsection{Capturing physiological processes of emotion regulation: Respiratory sinus arrhthymia}

A number of physiological indices of ER are available to psychological researchers (e.g., electroencephalogram, functional magnetic resonance imaging, cortisol assays), of which respiratory sinus arrhthymia (RSA) is the most commonly cited measure in research with adolescents (Beauchaine, 2015). RSA is a measure of beat-to-beat intervals in heart rate that occur in synchrony with respiration, which reflects changes in the balance between sympathetic and parasympathetic influences on the heart (Thayer et al., 2012). RSA provides an index of autonomic influence on prefrontal cortical activity and executive functioning, and, as such, represents a non-invasive measure of ER capacity (Thayer, Hansen, Saus-Rose, \& Johnsen, 
2009). More specifically, RSA is thought to represent an individual's physiological capacity to appropriately and flexibly meet environmental demands (Li et al., 2009; Rickard \& VellaBrodrick, 2014). Tonic RSA (i.e., taken at rest) is thought to represent a global measure of ER capacity, with higher values indicating a greater general aptitude for ER (Appelhans \& Leucken, 2006). Lower values, conversely, are predictive of mental ill-health (Beauchaine \& Thayer, 2015).

As an overall measure of regulatory capacity, tonic RSA may represent, for example, how successfully the body mobilizes cognitive and metabolic resources during times of stress (e.g., during a class presentation) and engages in restorative functions and reducing energy expenditure when environmental demands decrease (e.g., once the presentation is completed). The use of tonic RSA to assess ER capacity, in this regard, can be likened to the measurement of muscle mass as a proxy for overall body strength. Importantly, tonic RSA supports efficient cognitive ER processes, and thus contributes to effective ER above and beyond the use of ER capacities captured via self-report alone (Hildebrandt, McCall, Engen, \& Singer, 2016). More specifically, RSA is thought to facilitate effective cognitive processing of emotional experiences by enhancing executive functioning and impulse inhibition (Thayer et al., 2012; Park, Van Bavel, Vasey, \& Thayer, 2012). Thus, individual differences in RSA may reflect differences in the capacity to inhibit unhelpful responses to emotional stimuli and engage in more adaptive processes, which, in turn, is likely to promote differentiated and appropriately-matched responses to environmental stressors (Lang, Bradley, \& Cuthbert, 1990; Thayer \& Lane, 2009. Moreover, assessment of RSA can bypass the reporting biases associated with self-report and is considered an objective measure of ER capacity (Appelhans \& Leucken, 2006; Walker, Pfingst, Carnevali, Sgoifo, \& Nalivaiko, 2017).

In young adults, measures of RSA are found to be inversely related to self-reported ER difficulties (Williams et al., 2015) and markers of mental ill-health (Beauchaine, 2015). Notably, lower resting RSA is primarily linked to mental distress in young people diagnosed with or at high-risk of developing mental disorders (see review by Beauchaine, 2015). RSA may also protect against the detrimental effects of stress and enhance positive psychological functioning, with research of vulnerable youth finding that individuals with higher tonic RSA displayed greater resilience in the face of stress, and were rated as more popular with peers (Kim \& Cicchetti, 2010). Research with adult samples has also linked higher tonic RSA to increased recovery from stress (Souza et al., 2007; Souza et al., 2013). The ability to effectively regulate emotions and inhibit unhelpful impulses also contributes to successful social functioning, and RSA has been linked to social connectedness (Geisler, Kubiak, Siewert, \& Weber, 2013) in adults, in children (Patriquin, Lorenzi, Scarpa \& Bell, 2014), and in adolescents with autistic spectrum disorders (Patriquin, Scarpa, Friedman, \& Porges, 2013). It remains unclear, however, whether the buffering effect of higher tonic RSA against mental ill-health extends to nonclinical and community-based adolescent samples, and how RSA relates to a broader range of markers of positive psychological functioning in adolescent groups, for example, engagement, perseverance, and optimism. 


\subsection{The current study}

The current study aimed to address the aforementioned gaps in the literature by examining the cross-sectional relationship between ER and wellbeing in a healthy adolescent sample. Both positive and negative functioning are central to understanding resilience, wellbeing, and mental health in adolescent samples (Rickard, Chin, \& Vella-Brodrick, 2016). Therefore, to reflect the full spectrum of mental health (Keyes, 2005; Westerhoff \& Keyes, 2010), the relationship between ER and numerous measures of positive functioning and mental distress was examined. Consistent with best-practice recommendations (Beauchaine, 2015), a multimethod approach was used to measure ER by including both self-reported ER and RSA. The evaluation of self-reported ER provides access to the conscious strategies and unobservable processes typically used by individuals in the face of emotional experiences - that is, "top down" processes linked to ER. The inclusion of RSA, on the other hand, provides an objective, physiological measure marker of ER (Appelhans \& Leucken, 20006; Thayer et al., 2012). RSA circumvents a number of potential limitations of self-report (e.g., response biases, limited insight, motivational level), while also capturing "bottom-up" cortical and subcortical processes supporting the flexible, effective regulation of emotion (Park, et al., 2012).

Two empirical studies that have examined the association between RSA and other vagally-mediated measures of heart rate variability and self-reported ER found inverse correlations of small to medium magnitude between RSA and scales of the Difficulties in Emotion Regulation Scale (DERS), suggesting that, although related, each measure captures unique variance of the ER construct (Visted et al., 2017; Williams et al., 2015). It is yet to be determined which components of ER - cognitive appraisals about the ER capabilities or underlying physiological processes - are most relevant to domains of adolescent wellbeing. Thus, the incorporation of both methods extends previous research that has focused primarily on self-reported ER processes in youth, and aims to provide a more comprehensive picture of the relationship of ER processes to adolescent functioning. Understanding the relative contribution of RSA and self-reported ER to adolescent wellbeing may inform the development of targeted ER interventions to enhance specific domains of wellbeing in young people.

It was predicted that ER capacity, as measured by lower self-reported ER difficulties and higher tonic RSA, would be positively related to resilience and domains of wellbeing thought to support optimal psychological functioning (i.e., flourishing) in adulthood, including engagement, perseverance, optimism, connectedness, and happiness (Kern, Benson, Steinberg, \& Steinberg, 2016). Second, it was predicted that ER capacity, as measured by lower selfreported difficulties and higher tonic RSA, would be negatively related to symptoms of depression and anxiety.

\section{Method}

\subsection{Participants}

Participants were 187 secondary school students enrolled in Years 10 and 11 at one of five Victorian schools (two government, three independent), randomly selected to complete the ER assessments from a larger sample of approximately 600 students participating in a school-based 
evaluation of adolescent wellbeing. Of the initial sample, 65 did not complete the full assessment (i.e., RSA monitoring, wellbeing and ER questionnaires). Reasons for incomplete data included absence from school on the day of testing, internet dropout while completing online wellbeing surveys, or withdrawing from participation prior to completing all assessments. This resulted in a final sample of 119 students (52\% female, 87\% Australian, age range $14-18, M$ age $=15.73, S D=0.87)$.

\subsection{Procedure}

Informed consent was provided by both students and their guardians prior to participation. Wellbeing data were collected via an online assessment battery, which participants of the larger study completed as part of scheduled wellbeing classes at their respective schools. ER data was collected within a 2-week timeframe of the online assessment, and involved students individually presenting to a low-stimulus experimental room throughout the school day (8.30am-4pm). Participants were provided details of the testing procedure, and verbally provided informed consent. To assess tonic RSA, electrocardiography (ECG) and respiration data were recorded by a trained experimenter using an integrated computer system and software package (Nexxus-10, Mind Media, 2004-2006). Following RSA recording, participants then completed a self-report battery of ER questionnaires. The total duration for data collection was approximately 20 minutes per participant.

\subsection{Materials}

\section{Respiratory sinus arrhythmia (RSA).}

RSA occurs within the frequency of respiration $(0.15-0.40 \mathrm{~Hz})$, is considered a relatively stable measure of vagally-mediated heart rate variability (HRV, Li et al, 2009; Thayer \& Sternberg, 2010), and is an appropriate HRV measure for short-term recordings of 5 minutes (Task Force of the European Society of Cardiology, 1996).

To monitor RSA, researchers applied disposable electrodes in a standard lead 2 bipolar configuration, approximately $1 \mathrm{~cm}$ below the clavicle and on the lower ribcage (Berntson, Quigley, \& Lozano, 2007). Respiration rate and rhythm were monitored via a sensor positioned around the lower abdomen. A neutral breathing pacer program was used to standardize breathing rate and rhythm, and was set at the recommended rate of $9(<10)$ breaths per minute in order to yield maximum R-R interval power (Brown, Beightol, Koh, \& Eckberg, 1993). Given the potential for paced breathing to contribute to stress-related changes in RSA as a result of increased mental effort (Berntson et al., 1997), instructions were provided to participants to "try and breathe along with this pacer, however, if it feels difficult or unnatural, just breathe at a consistent, relaxed pace that feels right to you" (Kobayashi, 2009). Electrocardiography (ECG) and respiration data were then recorded at a sampling rate of $1000 \mathrm{~Hz}$ by an integrated system and software package (Nexxus-10, Mind Media, 2004-2006). As recommended for RSA assessments of short duration, 5 minutes of continuous recording was obtained while participants remained in a still, seated position (Quintana, Alvares, \& Heathers, 2016; Task Force of the European Society of Cardiology, 1996). RSA monitoring software was concealed 
from the participant during the recording, to avoid potentially confounding effects, including increased sympathetic arousal, distraction, or interference of respiration or heart rate via biofeedback processes.

Self-reported emotion regulation strategies

The Difficulties in Emotion Regulation Scale (DERS; Gratz \& Roemer, 2004) includes 36 items and six subscales designed to assess perceived difficulties in ER relating to a) awareness and understanding of emotions, b) acceptance of emotions, c) the ability to engage in goaldirected behavior when experiencing negative emotions, and d) access to effective ER strategies. Items are scored on a five-point Likert scale ranging from 1 (almost never) to 5 (almost always), with higher scores representing greater ER difficulties (example item "When I'm upset, I have difficulty controlling my behavior"). The six subscales represent specific problems with ER, including lack of emotional clarity (Clarity; $\alpha=.82$ ); lack of emotional awareness (Awareness; $\alpha=.81$ ); difficulties controlling impulsive behaviors when distressed (Impulses; $\alpha$ $=.89$ ); non-acceptance of emotional responses (Non acceptance; $\alpha=.94$ ); and limited access to effective emotion regulation strategies (Strategies; $\alpha=.91$ ). These subscales are then summed to calculate a total score (DERS total). The DERS has been validated for use in adolescent samples aged between 12 to 17 years (Neumann, van Lier, Gratz, \& Koot, 2010), and the DERS total demonstrated good internal consistency in the current study $(\alpha=.85)$.

Psychological wellbeing.

The EPOCH Measure of Adolescent Well-being (EPOCH; Kern, Benson, Steinberg, \& Steinberg, 2016) is a 20-item, multidimensional self-report measure of adolescent wellbeing that assesses five positive psychological characteristics thought to foster flourishing (i.e., optimal psychological functioning) in adulthood (Seligman, 2011). Items are rated on a five-point Likert scale, from 1 (almost never/not at all like me) to 5 (almost always/very much like me), and each scale is computed as the average of its four respective items. These scales measure engagement with valued activities (Engagement; $\alpha=.78$; e.g., "I get completely absorbed in what I am doing"); persistence in the face of challenges or to achieve goals (Perseverance; $\alpha=.81$; e.g., "I finish whatever I begin"); optimism (Optimism; $\alpha=.86$; e.g., "I am optimistic about my future"); connectedness to peers and loved ones (Connectedness; $\alpha=.88$; e.g., "There are people in my life who really care about $m e^{\prime \prime}$ ); and subjective feelings of happiness (Happiness; $\alpha=.90$; e.g., "I feel happy"). The EPOCH has been validated for use in adolescents aged between 10 and 18 years in Australia and the United States. Each scale has acceptable psychometric properties, including construct and discriminant validity (Kern, et al., 2016), and had acceptable internal consistency in the current sample $(\alpha=.78-.90)$.

Resilience

The Connor-Davidson Resilience Scale (CD-RISC; Campbell-Sills \& Stein, 2007) is a selfreport measure that conceptualizes resilience as positive adaptation following stress or adversity. It comprises 10 items (e.g., "I believe I can achieve my goals even if there are obstacles"), each of which is rated on a five-point scale ranging from 0 to 4 . Scores range from 0 to 40 , with higher scores reflecting greater resilience. The scale demonstrates excellent psychometric 
properties in late adolescent populations ( $M$ age $=18.8$; Campbell-Sills \& Stein, 2007). In the current study, it showed excellent internal consistency $(\alpha=.90)$.

Mental distress

The PHQ-4 (Löwe et al., 2010) is a four-item self-report screening tool used to detect the presence of core symptoms of depression and anxiety (e.g., "In the past two weeks, how often have you been bothered by feeling nervous, anxious, or on edge?"). Items are measured on a five-point Likert scale ranging from 0 (not at all) to 4 (nearly every day), with higher scores indicating the presence of greater mental distress. Scores on each scale range from 0 to 6 , with scores of 3 or above indicating the likely presence of depression or anxiety. The PHQ-4 has been validated for use in the general population aged 11 years and over (Kroenke, Spitzer, Williams \& Löwe, 2009). In the current study, the depression subscale demonstrated borderline internal consistency $(\alpha=.68)$, while the anxiety subscale showed good internal consistency $(\alpha=.83)$.

\section{Data analyses}

RSA data were generated and pre-processed using the Nexus software package (Mind Media, 2004-2006). The first 60 seconds of the 5-minute RSA recording was excluded from analysis, to ensure participants were settled and sufficiently relaxed. A time series of heart rate interbeat intervals (IBIs) were then generated. Raw IBIs were then screened for artifact using the following criteria: (1) IBIs were between 500 and $1500 \mathrm{~ms}$, and 2) IBIs differing by more than $25 \%$ from the previous IBI were considered an artifact and removed from analyses and replaced with interpolated data $(\mathrm{IBI}[\mathrm{n}]=(\mathrm{IBI}[\mathrm{n}-1]+\mathrm{IBI}) / 2) ;$ Mind Media, 2004-2006). The mean percentage of artifact removed from each participant was 3.6 seconds of data $(S D=5.90)$. The remaining 4 minutes of data were then processed in full, and RSA values (i.e., HRV in the highfrequency band of $0.15-0.40 \mathrm{~Hz}$ ) were extracted. RSA data was then log transformed to better approximate a normal distribution and meet assumptions of linear regression (Ellis, Sollers III, Edelstein, \& Thayer, 2008). RSA and self-report data were entered into SPSS for all statistical analyses (version 23, IBM Chicago, IL, USA).

Four randomly missing items on the DERS and CD-RISC questionnaires were substituted by the item mean score, rounded to a discrete value, before subscale and total scores were calculated for each participant as per scale-developer's instructions (Gratz \& Roemer, 2004). Two participants provided DERS scores \pm 2 standard deviations from the mean, which were imputed using the Winsor method (item mean $+(3 \times \mathrm{SD}))$. No outliers were detected in EPOCH, CD-RISC, PHQ-4 subscales or HRV data.

To identify potential confounds previously documented in the literature, including age, gender, ethnicity, and SES, independent t-tests were conducted with the variables of interest (Currie et al., 2009; Nolen-Hoeksema \& Girgus, 1994; Martinez \& Dukes, 1997). No significant differences $(p>.05)$ were found for gender or ethnicity on any of the examined measures of wellbeing, mental distress, or ER. Therefore, gender was not controlled for in subsequent analyses. As two of the privately funded schools were boarding schools, and two schools (one public, one private) shared a postcode, postcode-generated SES was considered to be an inappropriate measure of social privilege in the current sample. Instead, school funding type 
(public or private) was used as an index of SES. Significant between-group differences were found for school type on measures of mental distress, including PHQ-4 anxiety $(t(117)=4.64, p$ $<.001)$, PHQ-4 depression $(t(117)=4.96, p<.001)$, as well as RSA ( $t(117)=2.80, p<.01)$. Pearson's bivariate correlations showed significant relationships between age and variables including PHQ anxiety ( $r=-.453, p<.001)$, PHQ-4 depression $(r=-.399, p<.001)$, and RSA $(r=-.259, p<.01)$. Thus, age and school were statistically controlled for in all analyses.

A series of hierarchical multiple regression analyses were then conducted to assess the relationship between ER (RSA and self-reported DERS total) and each of the wellbeing variables. Step 1 included the covariates of age and school type. Step 2 included the cognitive and physiological ER variables (i.e., DERS total and RSA, respectively). Due to expected multicolinearity, independent regression analyses were run for each EPOCH scale. All performed tests were two-tailed and analysed at a significance level of $p<.05$.

\section{Results}

Descriptive statistics for ER, wellbeing, and demographic characteristics are presented in Table 1. Results are presented for the total sample, and stratified according to gender.

\section{Table 1.}

Descriptive statistics for emotion regulation, wellbeing \& mental distress variables, and demographic characteristics

\begin{tabular}{lccc}
\multicolumn{1}{c}{ Variable } & Total $(N=119)$ & Females $(n=62)$ & Males $(n=57)$ \\
& $M \pm S D$ & $M \pm S D$ & $M \pm S D$ \\
\hline DERS Total Score & $76.08 \pm 24.51$ & $79.16 \pm 28.94$ & $72.74 \pm 18.22$ \\
RSA & $3.52 \pm 0.50$ & $3.54 \pm 0.55$ & $3.50 \pm 0.45$ \\
EPOCH Engagement & $17.35 \pm 4.32$ & $16.90 \pm 4.47$ & $17.84 \pm 4.13$ \\
EPOCH & $16.97 \pm 4.33$ & $16.76 \pm 4.49$ & $17.19 \pm 4.18$ \\
Perseverance & & & \\
EPOCH Optimism & $17.64 \pm 4.87$ & $17.11 \pm 5.11$ & $18.23 \pm 4.56$ \\
EPOCH & $19.81 \pm 4.27$ & $20.26 \pm 4.36$ & $19.31 \pm 4.15$ \\
Connectedness & & & \\
EPOCH Happiness & $19.29 \pm 4.80$ & $19.26 \pm 5.01$ & $19.33 \pm 4.59$ \\
CD Resilience & $36.85 \pm 7.77$ & $36.18 \pm 8.03$ & $37.58 \pm 7.47$ \\
PHQ Depression & $2.60 \pm 1.87$ & $2.68 \pm 2.06$ & $2.51 \pm 1.66$ \\
PHQ Anxiety & $2.69 \pm 1.98$ & $2.81 \pm 2.25$ & $2.56 \pm 1.64$ \\
Age (years) & $15.73 \pm 0.87$ & $15.82 \pm 0.95$ & $15.63 \pm 0.77$ \\
\hline
\end{tabular}

Table 1 depicts the mean and standard deviation values on emotion regulation, wellbeing, and mental distress measures for the full sample, and stratified according to gender. DERS = Difficulties in Emotion Regulation Scale; RSA = log-transformed RSA; EPOCH = EPOCH Measure of Adolescent Wellbeing; CD Resilience = Connor-Davidson Resilience Scale; PHQ = Patient Health Questionnaire 4-item version 
Results of bivariate correlations showed a significant positive relationship between RSA and the EPOCH scale Perseverance $(r=0.24, p<.05)$ and CD-RISC Resilience $(r=0.21, p<.05)$. As predicted, significant negative relationships were found between DERS total scores (representing greater ER difficulties) and CD-RISC Resilience $(r=-0.36, p<.01)$, and all EPOCH scales. Significant positive relationships were found between DERS total scores and mental distress, as measured by PHQ-4 Depression $(r=0.46, p<$ $.01)$ and PHQ-4 Anxiety $(r=0.40, p<.01)$. A non-significant correlation was found between HRV and DERS total score $(r=0.05, p>.05)$. A correlation matrix of ER, wellbeing, and mental distress variables is presented in Table 2.

Table 2.

Correlation matrix of emotion regulation, wellbeing, and mental distress variables $(\mathrm{N}=119)$

\begin{tabular}{lllllllllll} 
Measure & 1 & 2 & 3 & 4 & 5 & 6 & 7 & 8 & 9 \\
\hline
\end{tabular}

DERS Total Score

(1)

$(2)$

EPOCH Engagement $\quad-.29^{* *} \quad .11$

(3)

$\begin{array}{lllll}\text { EPOCH Perseverance } & -.36^{* *} & .24^{*} & .77^{* *} & \\ \text { (4) } & & & & \\ \text { EPOCH Optimism } & -.40^{* *} & .09 & .82^{* *} & .80^{* *}\end{array}$

(5)

EPOCH Connectedness

(6)

EPOCH Happiness

(7)

CD Resilience

(8)

PHQ Depression

(9)

PHQ Anxiety

(10)

$\begin{array}{lllll}-.23^{*} & .13 & .55^{* *} & .63^{* *} & .71^{* *}\end{array}$

${ }^{*} p<.05^{* *} p<.01$

Table 2 shows bivariate (Pearson's $r$ ) correlation coefficients between emotion regulation, wellbeing, and mental distress variables. Statistically significant coefficients are presented in bold font. DERS = Difficulties in Emotion Regulation Scale; RSA = log-transformed RSA; EPOCH = EPOCH Measure of Adolescent Well-being; CD Resilience = Connor-Davidson Resilience Scale; $P H Q=$ Patient Health Questionnaire 4-item version.

Multiple hierarchical regression analyses showed that after controlling for age and school type, DERS total scores were significantly and negatively associated with all measures of wellbeing measures, consistent with our hypotheses. In relation to physiological ER, RSA was positively related to both EPOCH Perseverance and CD-RISC Resilience. Semi-partial correlations squared $\left(s r^{2}\right)$ revealed small to medium effect sizes for each significant predictor, which independently accounted for between $5 \%$ and $16 \%$ of the variance in wellbeing outcomes. A summary of the full hierarchical regression models in which both the DERS total score and RSA predicted wellbeing is presented in Tables 3a and 3b. 
Table 3a.

Hierarchical multiple regression models examining emotion regulation variables and wellbeing

\begin{tabular}{|c|c|c|c|c|c|c|c|c|c|}
\hline \multirow{2}{*}{$\begin{array}{l}\text { Hierarchical } \\
\text { regression step }\end{array}$} & \multirow{2}{*}{$\begin{array}{c}\text { EPOCH } \\
\text { Engagement }\end{array}$} & \multirow[b]{2}{*}{$B$} & \multirow[b]{2}{*}{$\beta$} & \multirow[b]{2}{*}{$t$} & \multirow[b]{2}{*}{$p$} & \multicolumn{2}{|c|}{$95 \%$ CI for } & \multirow[b]{2}{*}{$r$} & \multirow[b]{2}{*}{$s r^{2}$} \\
\hline & & & & & & Lower & Upper & & \\
\hline \multirow[t]{2}{*}{ Model 1} & Age & 0.02 & 0.01 & 0.04 & .97 & -1.26 & 1.31 & -.05 & .00 \\
\hline & School & -0.66 & -0.08 & -0.58 & .56 & -2.89 & 1.57 & -.07 & .00 \\
\hline \multicolumn{10}{|l|}{$R^{2}=.01(p=.73)$} \\
\hline \multirow[t]{4}{*}{ Model 2} & Age & 0.08 & 0.02 & 0.13 & .90 & -1.16 & 1.32 & -.05 & .00 \\
\hline & School & -0.50 & -0.06 & -0.46 & .65 & -2.65 & 1.65 & -.07 & .00 \\
\hline & DERS Total & -0.05 & -0.30 & -3.32 & .001 & -0.08 & -0.02 & -.29 & .09 \\
\hline & RSA & 1.00 & 0.12 & 1.26 & .21 & -0.57 & 2.57 & .11 & .01 \\
\hline \multicolumn{10}{|c|}{$R^{2}$ change $=.10(p=.003)$} \\
\hline \multirow{2}{*}{$\begin{array}{l}\text { Hierarchical } \\
\text { regression step }\end{array}$} & \multirow{2}{*}{$\begin{array}{c}\text { EPOCH } \\
\text { Perseverance }\end{array}$} & \multirow[b]{2}{*}{$B$} & \multirow[b]{2}{*}{$\beta$} & \multirow[b]{2}{*}{$t$} & \multirow[b]{2}{*}{$p$} & \multicolumn{2}{|c|}{$95 \% \mathrm{CI}$ for } & \multirow[b]{2}{*}{$r$} & \multirow[b]{2}{*}{$s r^{2}$} \\
\hline & & & & & & Lower & Upper & & \\
\hline \multirow[t]{2}{*}{ Model 1} & Age & -0.10 & -.02 & 0.15 & .88 & -1.21 & 1.19 & .06 & .00 \\
\hline & School & -0.45 & -.05 & 0.40 & .69 & -2.69 & 1.79 & .07 & .00 \\
\hline \multicolumn{10}{|l|}{$R^{2}=.01(p=.77)$} \\
\hline Model 2 & Age & 0.06 & .01 & 0.10 & .92 & -1.12 & 1.24 & .06 & .00 \\
\hline & School & -0.13 & -.01 & 0.12 & .90 & -2.17 & 1.92 & .07 & .00 \\
\hline & DERS Total & -0.07 & -.37 & 4.36 & .000 & -0.95 & -0.04 & .36 & .13 \\
\hline & RSA & 2.18 & .25 & 2.88 & .005 & 0.68 & 3.67 & .24 & .06 \\
\hline$R^{2}$ change $=.11$ & & & & & & & & & \\
\hline Hierarchical & EPOCH & & & & & $95 \%$ & I for & & \\
\hline regression step & Optimism & $B$ & $\beta$ & $t$ & $p$ & Lower & Upper & $r$ & $s r^{2}$ \\
\hline Model 1 & Age & 0.07 & 0.01 & 0.09 & .93 & -1.37 & 1.50 & -.08 & .00 \\
\hline & School & -1.28 & -0.13 & -1.02 & .31 & -3.78 & 1.22 & -.12 & .01 \\
\hline$R^{2}=.02(p=.41)$ & & & & & & & & & \\
\hline Model 2 & Age & 0.09 & 0.02 & 0.13 & .90 & -1.24 & 1.42 & -.08 & .00 \\
\hline & School & -1.14 & -0.12 & -0.98 & .33 & -3.44 & 1.17 & -.12 & .01 \\
\hline & DERS Total & -0.08 & -0.41 & -4.78 & .000 & -0.11 & -0.05 & -.40 & .16 \\
\hline & RSA & 0.80 & 0.08 & 0.94 & .35 & -0.88 & 2.49 & .09 & .01 \\
\hline$R^{2}$ change $=.17$ & & & & & & & & & \\
\hline Hierarchical & EPOCH & & & & & $95 \%$ & I for & & \\
\hline regression step & Connectedness & $B$ & $\beta$ & $t$ & $p$ & Lower & Upper & $r$ & $s r^{2}$ \\
\hline Model 1 & Age & -0.38 & -0.08 & -0.60 & .53 & -1.64 & 0.88 & -.13 & .00 \\
\hline & School & -0.68 & -0.08 & -0.61 & .54 & -2.86 & 1.51 & -.13 & .00 \\
\hline$R^{2}=.02(p=.30)$ & & & & & & & & & \\
\hline Model 2 & Age & -0.32 & -0.07 & -0.52 & .61 & -1.56 & 0.92 & -.13 & .00 \\
\hline & School & -0.54 & -0.06 & -0.50 & .62 & -2.68 & 1.61 & -.13 & .00 \\
\hline & DERS Total & -0.04 & -0.23 & -2.60 & .01 & -0.07 & -0.01 & -.23 & .05 \\
\hline & RSA & 0.90 & 0.11 & 1.14 & .26 & -0.67 & 2.47 & .13 & .01 \\
\hline$R^{2}$ change $=.06$ & & & & & & & & & \\
\hline
\end{tabular}


Table 3b.

Hierarchical multiple regression models examining emotion regulation variables and wellbeing

\begin{tabular}{|c|c|c|c|c|c|c|c|c|c|}
\hline \multirow{2}{*}{$\begin{array}{l}\text { Hierarchical } \\
\text { regression step }\end{array}$} & \multirow{2}{*}{$\begin{array}{c}\text { EPOCH } \\
\text { Happiness }\end{array}$} & \multirow[b]{2}{*}{$B$} & \multirow[b]{2}{*}{$\beta$} & \multirow[b]{2}{*}{$t$} & \multirow[b]{2}{*}{$p$} & \multicolumn{2}{|c|}{$95 \%$ CI for } & \multirow[b]{2}{*}{$r$} & \multirow[b]{2}{*}{$s r^{2}$} \\
\hline & & & & & & Lower & Upper & & \\
\hline \multirow[t]{2}{*}{ Model 1} & Age & 0.09 & 0.02 & 0.12 & .91 & -1.33 & 1.50 & -.10 & 0.00 \\
\hline & School & -1.55 & -0.16 & -1.25 & .21 & -4.00 & 0.90 & -.15 & 0.01 \\
\hline \multicolumn{10}{|l|}{$R^{2}=.02(p=.26)$} \\
\hline \multirow[t]{4}{*}{ Model 2} & Age & 0.16 & 0.03 & 0.23 & .82 & -1.18 & 1.50 & -.10 & 0.00 \\
\hline & School & -1.36 & -0.14 & -1.16 & .25 & -3.68 & 0.97 & -.15 & 0.01 \\
\hline & DERS Total & -0.07 & -0.34 & -3.87 & .000 & -0.10 & -0.03 & -.33 & 0.11 \\
\hline & RSA & 1.24 & 0.13 & 1.44 & .15 & -0.46 & 2.94 & .14 & 0.02 \\
\hline \multicolumn{10}{|c|}{$R^{2}$ change $=.12(p=.000)$} \\
\hline \multirow{2}{*}{$\begin{array}{l}\text { Hierarchical } \\
\text { regression step }\end{array}$} & \multirow[t]{2}{*}{ CD Resilience } & & & & & \multicolumn{2}{|c|}{$95 \% \mathrm{CI}$ for } & \multirow[b]{2}{*}{$r$} & \\
\hline & & $B$ & $\beta$ & $t$ & $p$ & Lower & & & $s r^{2}$ \\
\hline \multirow[t]{2}{*}{ Model 1} & Age & 3.19 & 0.36 & 2.83 & .005 & 0.96 & 5.42 & .12 & .06 \\
\hline & School & -5.13 & 0.33 & 2.62 & .01 & -9.00 & -1.26 & .08 & .06 \\
\hline \multicolumn{10}{|l|}{$R^{2}=.07(p=.01)$} \\
\hline \multirow[t]{4}{*}{ Model 2} & Age & 3.48 & 0.39 & 3.41 & .001 & 1.46 & 5.50 & .12 & .08 \\
\hline & School & -4.54 & 0.29 & 2.57 & .01 & -8.05 & -1.03 & .08 & .04 \\
\hline & DERS Total & -0.12 & -0.37 & -4.57 & .000 & -0.17 & -0.07 & -.36 & .14 \\
\hline & RSA & 3.97 & 0.26 & 3.06 & .003 & 1.40 & 6.53 & .21 & .06 \\
\hline
\end{tabular}

$R^{2}$ change $=.19(p=.001)$

Significant relationships between emotion regulation and measures of wellbeing are presented in bold font. DERS Total = Difficulties in Emotion Regulation Scale total score; RSA =log-transformed RSA; EPOCH = EPOCH Measure of Adolescent Wellbeing; CD Resilience = Connor-Davidson Resilience Scale; PHQ = Patient Health Questionnaire 4-item version.

As predicted, multiple hierarchical regression analyses revealed that after controlling for age and school type, DERS total scores were significantly and positively related to mental distress, as measured by PHQ4 Depression and Anxiety subscales. Semi-partial correlations squared $\left(s r^{2}\right)$ revealed medium effect sizes for self-reported ER (i.e., DERS total), which independently explained $21 \%$ of the variance in depression symptoms, and $15 \%$ of the variance in anxiety symptoms. RSA did not significantly predict symptoms of depression or anxiety. A summary of these analyses is presented in Table 4. 
Table 4.

Hierarchical multiple regression models examining emotion regulation variables and mental distress

\begin{tabular}{|c|c|c|c|c|c|c|c|c|c|}
\hline \multirow{2}{*}{$\begin{array}{l}\text { Hierarchical } \\
\text { regression step }\end{array}$} & PHQ Depression & $B$ & $\beta$ & $t$ & $p$ & \multicolumn{2}{|c|}{$\begin{array}{c}95 \% \text { CI for } \\
\text { Lower } \\
\text { Upper }\end{array}$} & $r$ & $s r^{2}$ \\
\hline & $\begin{array}{l}\text { Age } \\
\text { School }\end{array}$ & $\begin{array}{l}-0.45 \\
-1.01\end{array}$ & $\begin{array}{l}-0.21 \\
-0.27\end{array}$ & $\begin{array}{l}-1.79 \\
-2.30\end{array}$ & $\begin{array}{l}.08 \\
.02\end{array}$ & $\begin{array}{l}-0.95 \\
-1.88\end{array}$ & $\begin{array}{c}0.05 \\
-0.14\end{array}$ & $\begin{array}{l}-.40 \\
-.42\end{array}$ & $\begin{array}{l}.02 \\
.04\end{array}$ \\
\hline \multicolumn{10}{|l|}{$R^{2}=.196(p=.000)$} \\
\hline \multirow[t]{2}{*}{ Block 2} & $\begin{array}{l}\text { Age } \\
\text { School }\end{array}$ & $\begin{array}{l}-0.439 \\
-1.040\end{array}$ & $\begin{array}{l}-0.204 \\
-0.278\end{array}$ & $\begin{array}{l}-1.99 \\
-2.72\end{array}$ & $\begin{array}{l}.05 \\
.008\end{array}$ & $\begin{array}{l}-0.88 \\
-1.80\end{array}$ & $\begin{array}{c}-0.002 \\
-0.28\end{array}$ & $\begin{array}{l}-.40 \\
-.42\end{array}$ & $\begin{array}{l}.02 \\
.04\end{array}$ \\
\hline & $\begin{array}{l}\text { DERS Total } \\
\text { RSA }\end{array}$ & $\begin{array}{c}0.035 \\
-0.128\end{array}$ & $\begin{array}{l}0.457 \\
-0.034\end{array}$ & $\begin{array}{c}6.32 \\
-0.46\end{array}$ & $\begin{array}{l}.000 \\
.65\end{array}$ & $\begin{array}{c}0.02 \\
-0.68\end{array}$ & $\begin{array}{l}0.05 \\
0.43\end{array}$ & $\begin{array}{l}.46 \\
.11\end{array}$ & $\begin{array}{l}.21 \\
.00\end{array}$ \\
\hline$R^{2}$ change $=.21$ & & & & & & & & & \\
\hline
\end{tabular}

\begin{tabular}{|c|c|c|c|c|c|c|c|c|c|}
\hline \multirow{2}{*}{$\begin{array}{l}\text { Hierarchical } \\
\text { regression step }\end{array}$} & \multirow[t]{2}{*}{ PHQ Anxiety } & \multirow[b]{2}{*}{$B$} & \multirow[b]{2}{*}{$\beta$} & \multirow[b]{2}{*}{$t$} & \multirow[b]{2}{*}{$p$} & \multicolumn{2}{|c|}{$95 \%$ CI for } & \multirow[b]{2}{*}{$r$} & \multirow[b]{2}{*}{$s r^{2}$} \\
\hline & & & & & & Lower & & & \\
\hline \multirow[t]{2}{*}{ Block 1} & Age & -0.79 & -0.35 & -3.00 & .003 & -1.31 & -0.27 & -.45 & .06 \\
\hline & School & -0.59 & -0.15 & -1.30 & .20 & -1.50 & 0.31 & -.40 & .01 \\
\hline \multicolumn{10}{|l|}{$R^{2}=.22(p=.000)$} \\
\hline \multirow[t]{4}{*}{ Block 2} & Age & -0.78 & -0.35 & -3.27 & .001 & -1.26 & -0.31 & -.45 & .06 \\
\hline & School & -0.63 & -0.16 & -1.52 & .13 & -1.46 & 0.19 & -.40 & .01 \\
\hline & DERS Total & 0.03 & 0.39 & 5.26 & .000 & 0.02 & 0.04 & .40 & .15 \\
\hline & RSA & -0.19 & -0.05 & -0.05 & .54 & -0.79 & 0.42 & .10 & .00 \\
\hline
\end{tabular}

Significant relationships between emotion regulation and measures of mental distress are presented in bold font. DERS Total $=$

Difficulties in Emotion Regulation Scale total score, RSA = log-transformed RSA; PHQ = Patient Health Questionnaire

\section{Discussion}

This study examined the relationship between physiological and self-reported markers of ER and multiple measures of positive psychological functioning and mental distress in a normative adolescent sample. Specifically, we sought to clarify the strength and direction of relationships between ER using subjective and objective indices and dimensions of wellbeing, resilience, and symptoms of depression and anxiety.

\subsection{Emotion regulation and positive psychological functioning}

It was hypothesized that ER capacity, as measured by lower self-reported ER difficulties and higher tonic RSA, would be positively related to resilience and domains of wellbeing, including engagement, perseverance, optimism, connectedness, and happiness. As predicted, ER capacity significantly predicted numerous measures of wellbeing after controlling for the effects of age and school type, with small to medium effect sizes. Lower scores on the DERS total, indicative of poorer ER capacity, were inversely related to resilience and the wellbeing domains of perseverance, optimism, connectedness, and happiness. In addition, after controlling for the effects of age and school, significant positive relationships were found between RSA and resilience and perseverance. To our knowledge, this is the first study to examine the relationship between multiple measures of ER and wellbeing in a normative, school-based, adolescent sample. 
Results of this study indicate that ER is meaningfully related to aspects of positive psychological functioning in young people, with self-reported ER predictive of a broader range of wellbeing domains than RSA and with larger effect sizes. While previous research shows that deficits of ER contribute to mental distress and dysfunction, the current findings indicate that more adaptive ER profiles may also contribute to wellbeing in young people. Indeed, a selection of longitudinal research with adolescent and young adult samples supports this position and shows that ER capacity contributes to improvements in positive affect (i.e., Happiness; Yeung, Wong, \& Lok, 2011) and peer acceptance (i.e., Connectedness; Kim \& Cicchetti, 2010). Similarly, an adaptive, self-reported ER (positive refocusing) was found to mediate the relationship between optimism and subjective wellbeing (Yeung, Ho, \& Mak, 2015), while improvements in life satisfaction were found over a 9-month period in students displaying an adaptive cognitive coping style compared to those displaying less adaptive coping (Vella-Brodrick, Rickard, \& Chin, 2014). Further, ER strategies, including positive reappraisal (i.e., thinking about a challenging situation in a more positive manner) and attentional deployment (i.e., attending to non-threatening aspects of a situation) have been found to help individuals cope with a range of stressors across interpersonal and performance domains (Ivcevic \& Brackett, 2014; Libbrecht, Lievens, Carette, \& Côté, 2014; Troy \& Mauss, 2011). The current findings build upon past findings examining limited ER strategies by demonstrating that a broader suite of ER abilities, i.e., the ability to identify, select, and employ cognitive ER strategies, facilitates resilience and wellbeing in the face of stress and setbacks.

In addition to self-reported ER capacity, a novel contribution of this study is its examination of the relationship between an objective ER measure, RSA, and a comprehensive suite of measures of positive psychological functioning in young people. Previous examination of RSA specifically with adolescent samples has focused predominantly on negative aspects of functioning, such as mental illhealth (Beauchaine, 2015), antisocial behaviour (Beauchaine, Gatzke-Kopp, \& Mead, 2007), and self-harm (Weilgus, Aldrich, Mezulis, \& Crowell, 2016). Although there is increasing support for the role of RSA in social connectedness (Patriquin et al., 2014; Partiquin et al., 2013) and positive affect (Kok \& Fredrickson, 2010; Oveis et al., 2009), it has not previously been examined in relation to additional wellbeing domains outlined by the PERMA model. The current research thus contributes to existing literature outlining the relationship between RSA and wellbeing, and supports theory positing that higher tonic RSA can facilitate the flexible engagement of ER processes (Appelhans \& Leucken, 2006; Beauchaine \& Thayer, 2015).

Our results demonstrate significant positive relationships between resting RSA and self-reported resilience and perseverance. Resilience measures an individual's capacity for adaptive functioning following stress or adversity (Campbell-Sills \& Stein, 2007), whereas perseverance is characterized by tenacity in the face of challenges (Kern et al., 2016). Both abilities are supported by efficient corticalsubcortical integration, as reflected by high tonic RSA. To elaborate, RSA is thought to reflect output of the inhibitory cortico-subcortical neurocircuit of the central autonomic nervous system, which includes the brainstem, amygdala, insula, cingulate cortex, and prefrontal cortex (Davidson, Jackson, \& Kalin, 2000; Kemp \& Quintana, 2013). This neurocircuit is involved in the regulation of visceral responses to emotional stimuli, a process that recruits executive functions such as the selection and implementation of appropriate cognitive ER strategies (Thayer \& Lane, 2000, 2009). Resilience and perseverance are similar in that they involve adaptive functioning despite persistent or repeated exposure to emotionally challenging experiences, therefore, a strong capacity to regulate underlying physiological arousal may be particularly important in cultivating these domains of positive functioning. Interventions designed to enhance RSA, such as cultivating mindfulness (Chambers, Gullone, \& Allen, 2009), bio-feedback training 
(McCraty \& Zayas, 2014), and enhancing physical fitness (Routledge, Campbell, McFetridge-Durdle, \& Bacon, 2010), may be beneficial in bolstering resilience and perseverance in adolescent groups.

Consistent with this hypothesis, ER capacity can facilitate approach-behaviours in response to environmental stressors, such as persevering on a difficult homework assignment or managing ongoing interpersonal difficulties with teachers, peers, or parents (Troy \& Mauss, 2011). In the context of a broader body of positive psychological research, resilience and perseverance appear conceptually similar to the construct of grit, defined as perseverance and passion for long-term goals (Duckworth, Peterson, Matthews, \& Kelly, 2007). Results of a recent meta-analysis revealed that one facet of grit, perseverance of effort, predicts academic success after controlling for conscientiousness, a personality trait characterised by directedness and a will to achieve (Credé, Tynan, \& Harms, 2016; McCrae \& Costa, 1987). Further, it has been proposed that ER processes associated with RSA (e.g., the ability to inhibit strong emotional impulses), may share common underlying mechanisms with grit (Duckworth \& Gross, 2014). Together, these findings shed light on the role of both physiological and cognitive ER processes in resilience and perseverance in school-age adolescents, and provide a promising direction to bolster resilience in young people, for example, via explicit teaching of cognitive ER strategies or modifying RSA via structured training (e.g., McCraty \& Zayas, 2014).

\subsection{Emotion regulation and mental distress}

In relation to mental distress, we found moderate inverse relationships between self-reported ER capacity and depression and anxiety symptoms, after controlling for age and school type. Mental illhealth broadly involves the experience of one or more unpleasant emotions (e.g., sadness, fear) that is either too intense or endured for too long to be adaptive (Beauchaine et al., 2007). Difficulties identifying emotional distress, the belief that emotions are unchangeable, and the absence of adaptive ER strategies all represent ER difficulties that contribute to mental distress and disorder (De Castella et al., 2013; Hatzenbuehler, McLaughlin, \& Nol-Hoeksema, 2008). Unsurprisingly, deficits of ER are regarded as a transdiagnostic risk factor for the development of mental ill-health in both adults and adolescents (Aldao et al., 2010; McLaughlin, Hatzenbuehler, Mennin, \& Nolen-Hoeksema, 2011). Results of the current study show that moderate relationships between ER difficulties and mental distress exist even in a healthy, normative sample of young people (see also Garnefski, Kraaij, \& van Etten, 2005; Garnefski, Legerstee, Kraaij, Van Den Kommer, \& Teerds, 2002; Silk, et al., 2003). Based on these findings, it appears that mental health promotion for young people would benefit from including a greater emphasis on ER skills training, for example, increasing one's ability to acknowledge, identify, and actively modify difficult emotional experiences. These skills can be effectively taught in relatively brief training programs (Berking et al., 2008), and may be built into existing mental health interventions accessible to a broad adolescent population, such as school-based social emotional learning programs (Hamilton \& Hamilton, 2009).

\subsection{Covariance of self-reported ER and RSA}

The experience and regulation of emotion is thought to involve coordinated responses across subjective, cognitive, behavioral, and physiological measures (Marsh, Beauchaine \& Williams, 2008). Results of the current study revealed negligible covariance between subjective reports of ER capacity and RSA $(r=.05)$, suggesting that each measure captures distinct processes contributing to ER. These findings differ from previous research that reported significant, inverse, small to medium sized correlations between ER difficulties and a tonic measure of RSA in young adult samples in Norway (Visted et al., 2017) and the USA (Williams et al., 2015). Further research is needed to explore differences between the examined 
samples that may have contributed to these disparate results, such as the age of participants. Broader examination of the literature reveals that low covariance between experiential and physiological measures of emotion and related processes is commonly cited (Bonnano \& Keltner, 2004; Evers et al., 2014), leading some researchers to conclude that the correlation between emotional response systems is weak in the absence of intense emotional experiences or very specific contexts (Crowell et al., 2014; Mauss, Levenson, McCarter, Wilhelm, \& Gross, 2005). For example, Evers et al. (2014) draw upon the dual process framework, which proposes that psychological responses comprise two largely independent processes - one automatic (e.g., physiological processes) and one reflective (e.g., subjective, experiential processes) - and demonstrate that low coherence exists between automatic (e.g., RSA) and reflective measures (e.g., self-report). Such findings reinforce the importance of adopting a multi-method approach to ER research in order to capture a range of ER processes, while also bringing into question the appropriateness of comparing research that has measured ER with considerably different measures. (For a discussion of this issue, see Cole et al., 2004; Naragon-Gainey et al., 2017.)

As this study involved cross-sectional data taken at a particular point in the school year, it cannot be determined whether the identified associations between ER and wellbeing represent stable relationships or if ER capacity plays a causal role in the development of adolescent wellbeing. This is a notable limitation. Further, longitudinal research is required to clarify whether ER capacity contributes to differences in wellbeing outcomes over time. Due to the small sample, which predominantly comprised Australian-born adolescents from English-speaking backgrounds, the generalizability of our findings to other adolescent groups is restricted. Certain factors thought to influence RSA could not be statistically controlled for in this study. These include variation in the time that RSA was assessed (i.e., at different times throughout the school day), body mass index, and possible caffeine, nicotine, or medication use by participants (Quintana \& Heathers, 2014). It is likely that the use of a school sample limited potential variation on a number of these variables (e.g., caffeine and nicotine intake), however, results should be interpreted with these caveats in mind. Finally, the potential influence of common error variance in explaining the relationship between the self-report scales examined in this study, specifically between ER and wellbeing, may have contributed to the current findings and must be considered.

Despite these limitations, results of the current study position ER, and, in particular, self-reported ER strategies, as an important contributor to wellbeing in youth. Cultivating a young person's repertoire of adaptive ER skills and strategies may be a promising target for interventions aiming to enhance wellbeing in adolescent populations, including treatments that seek to reduce symptoms of mental distress (Morrish et al., 2018). Our findings may be of particular relevance to school-based socialemotional literacy platforms, which represent early intervention programs seeking to enhance psychological health within a school cohort of students. Furthermore, the moderate correlations found between self-reported ER and EPOCH wellbeing domains suggest that youth-focused interventions seeking to enhance wellbeing might be further enhanced by including a greater focus on adaptive ER strategies (see also Lü, Wang, \& Liu, 2013; Weytens, Luminet, Verhofstadt, \& Mikolajczak, 2014). Due to their association with both physiological and self-reported ER, the current findings suggest that cultivating young people's ER capacity - both via physiological markers and self-reported strategy use may provide a particularly valuable supplement to intervention programs seeking to bolster resilience and perseverance in the face of stress (Souza et al., 2013; Troy \& Mauss, 2011). These qualities are key to positive psychological functioning, and foster success across key challenges of adolescence, including academic performance and navigating important life transitions (Zolkoski \& Bullock, 2012). Future research should explore the predictive value of specific ER skills and strategies to wellbeing, occurring across the various stages of the emotion-generation cycle (see Ochsner et al., 2009; Ochsner \& Gross, 
2005). Experimental designs that examine the impact of enhancing student's cognitive and physiological ER capacity on wellbeing outcomes are also recommended.

In sum, the current study provides clear support for the relevance of self-reported, cognitive ER capacity to young people's wellbeing and mental distress. It also adds uniquely to the existing literature by evidencing the contribution of RSA, a physiological marker of ER capacity, to both resilience and perseverance in a healthy youth sample. Recognising the relevance of both self-reported and physiological ER processes to positive psychological functioning in adolescents broadens the scope for ER-oriented interventions, which may be used to complement and enhance existing preventative and early intervention treatment approaches that aim to bolster adolescent wellbeing and encourage flourishing throughout adulthood.

\section{Authors}

Lucy Morrish

Centre for Positive Psychology, Graduate School of Education, The University of Melbourne morrishl@unimelb.edu.au

Tan Chyuan Chin

Centre for Positive Psychology, Graduate School of Education, The University of Melbourne

Nikki Rickard

Centre for Positive Psychology, Graduate School of Education, The University of Melbourne School of Psychological Sciences, Monash University

Peta Sigley-Taylor

Centre for Positive Psychology, Graduate School of Education, The University of Melbourne

Dianne Anne Vella-Brodrick

Centre for Positive Psychology, Graduate School of Education, The University of Melbourne

\section{Acknowledgements}

This work was supported by the Australian Research Council under grant number LP130100357. The authors would like to acknowledge Dr. Paul Badcock and the anonymous reviewers for their valuable feedback during the production of this manuscript.

\section{Publishing Timeline}

Received 18 May 2018

Accepted 9 December 2018

Published 9 July

\section{References}

Adrian, M., Zeman, J., \& Veits, G. (2011). Methodological implications of the affect revolution: A 35-year review of emotion regulation assessment in children. Journal of Experimental Child Psychology, 110(2), 171-197. https://doi.org/10.1016/j.jecp.2011.03.009

Aldao, A., Nolen-Hoeksema, S., \& Schweizer, S. (2010). Emotion-regulation strategies across psychopathology: A meta-analytic review. Clinical Psychology Review, 30(2), 217-237. https://doi.org/10.1016/j.cpr.2009.11.004 
Appelhans, B. M., \& Luecken, L. J. (2006). Heart rate variability as an index of regulated emotional responding. Review of General Psychology, 10(3), 229-240. https://doi.org/10.1037/10892680.10.3.229

Beauchaine, T. P. (2015). Future directions in emotion dysregulation and youth psychopathology. Journal of Clinical Child \& Adolescent Psychology, 44(5), 875-896. https://doi.org/10.1080/15374416.2015.1038827

Beauchaine, T. P., Gatzke-Kopp, L., \& Mead, H. K. (2007). Polyvagal theory and developmental psychopathology: Emotion dysregulation and conduct problems from preschool to adolescence. Biological Psychology, 74(2), 174-184. https://doi.org/10.1016/j.biopsycho.2005.08.008

Beauchaine, T. P., \& Thayer, J. F. (2015). Heart rate variability as a transdiagnostic biomarker of psychopathology. International Journal of Psychophysiology, 98(2), 338-350. https://doi.org/10.1016/j.ijpsycho.2015.08.004

Berking, M., \& Wupperman, P. (2012). Emotion regulation and mental health: Recent findings, current challenges, and future directions. Current Opinion in Psychiatry, 25(2), 128-134. https://doi.org/10.1097/yco.0b013e3283503669

Berking, M., Wupperman, P., Reichardt, A., Pejic, T., Dippel, A., \& Znoj, H. (2008). Emotion-regulation skills as a treatment target in psychotherapy. Behaviour Research and Therapy, 46(11), 1230-1237. https://doi.org/10.1016/j.brat.2008.08.005

Berntson, G. G., Quigley, K. S., \& Lozano, D. (2007). Cardiovascular psychophysiology. Handbook of Psychophysiology, 3, 182-210. https://doi.org/10.1017/9781107415782.009

Berntson, G. G., Thomas Bigger, J., Eckberg, D. L., Grossman, P., Kaufmann, P. G., Malik, M., . . \& \&er Molen, M. W. (1997). Heart rate variability: origins, methods, and interpretive caveats. Psychophysiology, 34(6), 623-648. https://doi.org/10.1111/j.1469-8986.1997.tb02140.x

Bonanno, G., \& Keltner, D. (2004). Brief Report: The coherence of emotion systems: Comparing "on-line" measures of appraisal and facial expressions, and self-report. Cognition and Emotion, 18(3), 431444. https://doi.org/10.1080/02699930341000149

Brown, T. E., Beightol, L. A., Koh, J., \& Eckberg, D. L. (1993). Important influence of respiration on human RR interval power spectra is largely ignored. Journal of Applied Physiology, 75(5), 23102317. https://doi.org/10.1152/jappl.1993.75.5.2310

Campbell-Sills, L., \& Stein, M. B. (2007). Psychometric analysis and refinement of the Connor-Davidson Resilience Scale (CD-RISC): Validation of a 10-item measure of resilience. Journal of Traumatic Stress, 20(6), 1019-1028. https://doi.org/10.1002/jts.20271

Casey, B. J., Jones, R. M., \& Hare, T. A. (2008). The adolescent brain. Annals of the New York Academy of Sciences, 1124(1), 111-126.

Chambers, R., Gullone, E., \& Allen, N. B. (2009). Mindful emotion regulation: An integrative review. Clinical Psychology Review, 29(6), 560-572. https://doi.org/10.1016/j.cpr.2009.06.005

Cole, P. M., Martin, S. E., \& Dennis, T. A. (2004). Emotion regulation as a scientific construct: Methodological challenges and directions for child development research. Child Development, 75(2), 317-333. https://doi.org/10.1111/j.1467-8624.2004.00673.x

Connor, K. M., \& Davidson, J. R. (2003). Development of a new resilience scale: The Connor-Davidson Resilience Scale (CD-RISC). Depression and Anxiety, 18(2), 76-82. https://doi.org/10.1002/da.10113

Credé, M., Tynan, M. C., \& Harms, P. D. (2017). Much ado about grit: A meta-analytic synthesis of the grit literature. Journal of Personality and Social Psychology, 113(3), 492-511.

http://dx.doi.org/10.1037/pspp0000102 
Crowell, S. E., Baucom, B. R., Yaptangco, M., Bride, D., Hsiao, R., McCauley, E., \& Beauchaine, T. P. (2014). Emotion dysregulation and dyadic conflict in depressed and typical adolescents: Evaluating concordance across psychophysiological and observational measures. Biological Psychology, 98, 50-58. https://doi.org/10.1016/j.biopsycho.2014.02.009

Currie, C., Zanotti, C., Morgan, A., Currie, D., de Looze, M., Roberts, C., . . \& Barnekow, V. (2009). Social determinants of health and well-being among young people. Health Behaviour in School-aged Children (HBSC) Study: International report from 2010, 271. https://doi.org/10.1007/s00038-009-5404$\mathrm{X}$

Davidson, R. J., Jackson, D. C., \& Kalin, N. H. (2000). Emotion, plasticity, context, and regulation: Perspectives from affective neuroscience. Psychological Bulletin, 126(6), 890-909. https://doi.org/10.1037//0033-2909.126.6.890

Davidson, R. J., Putnam, K. M., \& Larson, C. L. (2000). Dysfunction in the neural circuitry of emotion regulation - a possible prelude to violence. Science, 289(5479), 591-594. https://doi.org/10.1126/science.289.5479.591

De Castella, K., Goldin, P., Jazaieri, H., Ziv, M., Dweck, C. S., \& Gross, J. J. (2013). Beliefs about emotion: Links to emotion regulation, well-being, and psychological distress. Basic and Applied Social Psychology, 35(6), 497-505. https://doi.org/10.1080/01973533.2013.840632

DeSteno, D., Gross, J. J., \& Kubzansky, L. (2013). Affective science and health: The importance of emotion and emotion regulation. Health Psychology, 32(5), 474-486. https://doi.org/10.1037/a0030259

Duckworth, A. L., Peterson, C., Matthews, M. D., \& Kelly, D. R. (2007). Grit: Perseverance and passion for long-term goals. Journal of Personality and Social Psychology, 92(6), 1087-1101. https://doi.org/10.1037/0022-3514.92.6.1087

Duckworth, A., \& Gross, J. J. (2014). Self-control and grit: Related but separable determinants of success. Current Directions in Psychological Science, 23(5), 319-325. https://doi.org/10.1177/0963721414541462

Ellis, R. J., Sollers , J. J., III, Edelstein, E. A., \& Thayer, J. F. (2008). Data transforms for spectral analyses of heart rate variability. Biomedical Scientific Instrumentation, 44, 392-397.

Evers, C., Hopp, H., Gross, J. J., Fischer, A. H., Manstead, A. S., \& Mauss, I. B. (2014). Emotion response coherence: A dual-process perspective. Biological Psychology, 98, 43-49. https://doi.org/10.1016/j.biopsycho.2013.11.003

Fredrickson, B. L., Tugade, M. M., Waugh, C. E., \& Larkin, G. R. (2003). What good are positive emotions in crisis? A prospective study of resilience and emotions following the terrorist attacks on the United States on September 11th, 2001. Journal of Personality and Social Psychology, 84(2), 365-376. https://doi.org/10.1037//0022-3514.84.2.365

Garnefski, N., Kraaij, V., \& Spinhoven, P. (2001). Negative life events, cognitive emotion regulation and emotional problems. Personality and Individual Differences, 30(8), 1311-1327. https://doi.org/10.1016/s0191-8869(00)00113-6

Garnefski, N., Kraaij, V., \& van Etten, M. (2005). Specificity of relations between adolescents' cognitive emotion regulation strategies and internalizing and externalizing psychopathology. Journal of Adolescence, 28(5), 619-631. https://doi.org/10.1016/j.adolescence.2004.12.009

Garnefski, N., Legerstee, J., Kraaij, V., Van Den Kommer, T., \& Teerds, J. A. N. (2002). Cognitive coping strategies and symptoms of depression and anxiety: A comparison between adolescents and adults. Journal of Adolescence, 25(6), 603-611. https://doi.org/10.1006/jado.2002.0507 
Geisler, F. C., Kubiak, T., Siewert, K., \& Weber, H. (2013). Cardiac vagal tone is associated with social engagement and self-regulation. Biological Psychology, 93(2), 279-286.

https://doi.org/10.1016/j.biopsycho.2013.02.013

Gratz, K. L., \& Roemer, L. (2004). Multidimensional assessment of emotion regulation and dysregulation: Development, factor structure, and initial validation of the difficulties in emotion regulation scale. Journal of Psychopathology and Behavioral Assessment, 26(1), 41-54. https://doi.org/10.1023/b:joba.0000007455.08539.94

Gratz, K. L., Weiss, N. H., \& Tull, M. T. (2015). Examining emotion regulation as an outcome, mechanism, or target of psychological treatments. Current Opinion in Psychology, 3, 85-90. https://doi.org/10.1016/j.copsyc.2015.02.010

Graziano, P., \& Derefinko, K. (2013). Cardiac vagal control and children's adaptive functioning: A metaanalysis. Biological Psychology, 94(1), 22-37. https://doi.org/10.1016/j.biopsycho.2013.04.011

Gross, J. J., \& John, O. P. (2003). Individual differences in two emotion regulation processes: Implications for affect, relationships, and well-being. Journal of Personality and Social Psychology, 85(2), 348-362. https://doi.org/10.1037/0022-3514.85.2.348

Halligan, S. L., Cooper, P. J., Fearon, P., Wheeler, S. L., Crosby, M., \& Murray, L. (2013). The longitudinal development of emotion regulation capacities in children at risk for externalizing disorders. Development and Psychopathology, 25(2), 391-406. https://doi.org/10.1017/s0954579412001137

Hamilton, S., \& Hamilton, M. (2009). The transition to adulthood: Challenges of poverty and structural lag. In R. Lerner \& L. Steinberg (Eds.), Handbook of Adolescent Psychology (3rd ed.), pp. 492-526. https://doi.org/10.1002/9780470479193.adlpsy002015

Hatzenbuehler, M. L., McLaughlin, K. A., \& Nol-Hoeksema, S. (2008). Emotion regulation and internalizing symptoms in a longitudinal study of sexual minority and heterosexual adolescents. Journal of Child Psychology and Psychiatry, 49(12), 1270-1278. https://doi.org/10.1111/j.1469-7610.2008.01924.x

Hildebrandt, L. K., McCall, C., Engen, H. G., \& Singer, T. (2016). Cognitive flexibility, heart rate variability, and resilience predict fine-grained regulation of arousal during prolonged threat. Psychophysiology, 53(6), 880-890. https://doi.org/10.1111/psyp.12632

Huppert, F. A. (2009). Psychological well-being: Evidence regarding its causes and consequences. Applied Psychology: Health and Well-Being, 1(2), 137-164. https://doi.org/10.1111/j.1758-0854.2009.01008.x

Ivcevic, Z., \& Brackett, M. (2014). Predicting school success: Comparing conscientiousness, grit, and emotion regulation ability. Journal of Research in Personality, 52, 29-36. https://doi.org/10.1016/j.jrp.2014.06.005

Kemp, A. H., \& Quintana, D. S. (2013). The relationship between mental and physical health: Insights from the study of heart rate variability. International Journal of Psychophysiology, 89(3), 288-296. https://doi.org/10.1016/j.ijpsycho.2013.06.018

Kern, M. L., Benson, L., Steinberg, E. A., \& Steinberg, L. (2016). The EPOCH measure of adolescent wellbeing. Psychological Assessment, 28(5), 586-597. https://doi.org/10.1037/t50588-000

Keyes, C. L. (2005). Mental illness and/or mental health? Investigating axioms of the complete state model of health. Journal of Consulting and Clinical Psychology, 73(3), 539-548. https://doi.org/10.1037/0022-006x.73.3.539

Kim, J., \& Cicchetti, D. (2010). Longitudinal pathways linking child maltreatment, emotion regulation, peer relations, and psychopathology. Journal of Child Psychology and Psychiatry, 51(6), 706-716. https://doi.org/10.1111/j.1469-7610.2009.02202.x 
Kobayashi, H. (2009). Does paced breathing improve the reproducibility of heart rate variability measurements? Journal of Physiological Anthropology, 28(5), 225-230. https://doi.org/10.2114/jpa2.28.225

Kok, B. E., \& Fredrickson, B. L. (2010). Upward spirals of the heart: Autonomic flexibility, as indexed by vagal tone, reciprocally and prospectively predicts positive emotions and social connectedness. Biological Psychology, 85(3), 432-436. https://doi.org/10.1016/j.biopsycho.2010.09.005

Koval, P., Ogrinz, B., Kuppens, P., Van den Bergh, O., Tuerlinckx, F., \& Sütterlin, S. (2013). Affective instability in daily life is predicted by resting heart rate variability. PloS one, 8(11), e81536. https://doi.org/10.1371/journal.pone.0081536

Kroenke, K., Spitzer, R. L., Williams, J. B., \& Löwe, B. (2009). An ultra-brief screening scale for anxiety and depression: The PHQ-4. Psychosomatics, 50(6), 613-621. https://doi.org/10.1016/s00333182(09)70864-3

Lang, P. J., Bradley, M. M., \& Cuthbert, B. N. (1990). Emotion, attention, and the startle reflex. Psychological Review, 97(3), 377-395. http://dx.doi.org/10.1037/0033-295X.97.3.377

Li, Z., Snieder, H., Su, S., Ding, X., Thayer, J. F., Treiber, F. A., \& Wang, X. (2009). A longitudinal study in youth of heart rate variability at rest and in response to stress. International Journal of Psychophysiology, 73(3), 212-217. https://doi.org/10.1016/j.ijpsycho.2009.03.002

Libbrecht, N., Lievens, F., Carette, B., \& Côté, S. (2014). Emotional intelligence predicts success in medical school. Emotion, 14(1), 64-73. https://doi.org/10.1037/a0034392

Löwe, B., Wahl, I., Rose, M., Spitzer, C., Glaesmer, H., Wingenfeld, K., . . \& Brähler, E. (2010). A 4-item measure of depression and anxiety: Validation and standardization of the Patient Health Questionnaire-4 (PHQ-4) in the general population. Journal of Affective Disorders, 122(1), 86-95. https://doi.org/10.1016/j.jad.2009.06.019

Lü, W., Wang, Z., \& Liu, Y. (2013). A pilot study on changes of cardiac vagal tone in individuals with low trait positive affect: The effect of positive psychotherapy. International Journal of Psychophysiology, 88(2), 213-217. https://doi.org/10.1016/j.ijpsycho.2013.04.012

Marsh, P., Beauchaine, T. P., \& Williams, B. (2008). Dissociation of sad facial expressions and autonomic nervous system responding in boys with disruptive behavior disorders. Psychophysiology, 45(1), 100-110. https://doi.org/10.1111/j.1469-8986.2007.00603.x

Martinez, R. O., \& Dukes, R. L. (1997). The effects of ethnic identity, ethnicity, and gender on adolescent well-being. Journal of Youth and Adolescence, 26(5), 503-516.

Mauss, I. B., Levenson, R. W., McCarter, L., Wilhelm, F. H., \& Gross, J. J. (2005). The tie that binds? Coherence among emotion experience, behavior, and physiology. Emotion, 5(2), 175-190. https://doi.org/10.1037/1528-3542.5.2.175

McCrae, R. R., \& Costa, P. T. (1987). Validation of the five-factor model of personality across instruments and observers. Journal of Personality and Social Psychology, 52(1), 81-90. https://doi.org/10.1037//0022-3514.52.1.81

McCraty, R., \& Zayas, M. A. (2014). Cardiac coherence, self-regulation, autonomic stability, and psychosocial well-being. Frontiers in Psychology, 5, 1-13. https://doi.org/10.3389/fpsyg.2014.01090

McLaughlin, K. A., Hatzenbuehler, M. L., Mennin, D. S., \& Nolen-Hoeksema, S. (2011). Emotion dysregulation and adolescent psychopathology: A prospective study. Behaviour Research and Therapy, 49(9), 544-554. https://doi.org/10.1016/j.brat.2011.06.003

Mind Media. (2004). BioTrace + Software Manual for NeXus-10. The Netherlands: Mind Media BV. 
Morrish, L., Rickard, N., Chin, T. C., \& Vella-Brodrick, D. A. (2018). Emotion regulation in adolescent well-being and positive education. Journal of Happiness Studies, 19(5), 1543-1564. http://doi.org 10.1007/s10902-017-9881-y

Neumann, A., van Lier, P. A., Gratz, K. L., \& Koot, H. M. (2010). Multidimensional assessment of emotion regulation difficulties in adolescents using the difficulties in emotion regulation scale. Assessment, 17(1), 138-149. https://doi.org/10.1177/1073191109349579

Nolen-Hoeksema, S., \& Girgus, J. S. (1994). The emergence of gender differences in depression during adolescence. Psychological Bulletin, 115(3), 424-443. https://doi.org/10.1037//0033-2909.115.3.424

Ochsner, K. N., \& Gross, J. J. (2005). The cognitive control of emotion. Trends in Cognitive Sciences, 9(5), 242-249. https://doi.org/10.1016/j.tics.2005.03.010

Ochsner, K. N., Ray, R. R., Hughes, B., McRae, K., Cooper, J. C., Weber, J., . . \& Gross, J. J. (2009). Bottomup and top-down processes in emotion generation: Common and distinct neural mechanisms. Psychological Science, 20(11), 1322-1331. https://doi.org/10.1111/j.1467-9280.2009.02459.x

Oveis, C., Cohen, A. B., Gruber, J., Shiota, M. N., Haidt, J., \& Keltner, D. (2009). Resting respiratory sinus arrhythmia is associated with tonic positive emotionality. Emotion, 9(2), 265-270. https://doi.org/10.1037/a0015383

Park, G., Van Bavel, J. J., Vasey, M. W., \& Thayer, J. F. (2012). Cardiac vagal tone predicts inhibited attention to fearful faces. Emotion, 12(6), 1292-1302. https://doi.org/ 10.1037/a0028528

Patriquin, M. A., Lorenzi, J., Scarpa, A., \& Bell, M. A. (2014). Developmental trajectories of respiratory sinus arrhythmia: Associations with social responsiveness. Developmental Psychobiology, 56(3), 317-326. https://doi.org/10.1002/dev.21100

Patriquin, M. A., Scarpa, A., Friedman, B. H., \& Porges, S. W. (2013). Respiratory sinus arrhythmia: A marker for positive social functioning and receptive language skills in children with autism spectrum disorders. Developmental Psychobiology, 55(2), 101-112. https://doi.org/10.1002/dev.21002

Quintana, D. S., Alvares, G. A., \& Heathers, J. A. J. (2016). Guidelines for Reporting Articles on Psychiatry and Heart rate variability (GRAPH): Recommendations to advance research communication. Translational Psychiatry, 6(5), 1-10. https://doi.org/10.1038/tp.2016.73

Quintana, D. S., \& Heathers, J. A. (2014). Considerations in the assessment of heart rate variability in biobehavioral research. Frontiers in Psychology, 5, 1-10. https://doi.org/10.3389/fpsyg.2014.00805

Quoidbach, J., Berry, E. V., Hansenne, M., \& Mikolajczak, M. (2010). Positive emotion regulation and well-being: Comparing the impact of eight savoring and dampening strategies. Personality and Individual Differences, 49(5), 368-373. https://doi.org/10.1016/j.paid.2010.03.048

Quoidbach, J., Mikolajczak, M., \& Gross, J. J. (2015). Positive interventions: An emotion regulation perspective. Psychological Bulletin, 141(3), 655-693. https://doi.org/10.1037/a0038648

Rickard, N. S., Chin, T. C., \& Vella-Brodrick, D. A. (2016). Cortisol awakening response as an index of mental health and well-being in adolescents. Journal of Happiness Studies, 17(6), 2555-2568. https://doi.org/10.1007/s10902-015-9706-9

Rickard, N. S., \& Vella-Brodrick, D. A. (2014). Changes in well-being: Complementing a psychosocial approach with neurobiological insights. Social Indicators Research, 117(2), 437-457. https://doi.org 10.1007/s11205-013-0353-4

Routledge, F. S., Campbell, T. S., McFetridge-Durdle, J. A., \& Bacon, S. L. (2010). Improvements in heart rate variability with exercise therapy. Canadian Journal of Cardiology, 26(6), 303-312. https://doi.org/10.1016/s0828-282x(10)70395-0 
Ryff, C. D., \& Keyes, C. L. M. (1995). The structure of psychological well-being revisited. Journal of Personality and Social Psychology, 69(4), 719-727. https://doi.org/10.1037//0022-3514.69.4.719

Seligman, M. (2011). Flourish. Sydney, Australia: William Heinemann.

Silk, J. S., Steinberg, L., \& Morris, A. S. (2003). Adolescents' emotion regulation in daily life: Links to depressive symptoms and problem behavior. Child Development, 74(6), 1869-1880. https://doi.org/10.1046/j.1467-8624.2003.00643.x

Souza, G., Magalhães, L., Da Cruz, T., Mendonça-De-Souza, A., Duarte, A., Fischer, N., . . \& Volchan, E. (2013). Resting vagal control and resilience as predictors of cardiovascular allostasis in peacekeepers. Stress, 16(4), 377-383. https://doi.org/10.3109/10253890.2013.767326

Souza, G., Mendonça-de-Souza, A., Barros, E., Coutinho, E., Oliveira, L., Mendlowicz, M., ... \& Volchan, E. (2007). Resilience and vagal tone predict cardiac recovery from acute social stress. Stress, 10(4), 368-374. https://doi.org/10.1080/10253890701419886

Steinberg, L. (2016). Adolescence (11th ed.). New York, NY: McGraw Hill.

Task Force of the European Society of Cardiology. (1996). The North American Society of Pacing and Electrophysiology: Heart rate variability: standards of measurement, physiological interpretation and clinical use. Circulation, 93(5), 1043-1065. https://doi.org/10.1161/01.cir.93.5.1043

Thayer, J. F., Åhs, F., Fredrikson, M., Sollers, J. J., III, \& Wager, T. D. (2012). A meta-analysis of heart rate variability and neuroimaging studies: Implications for heart rate variability as a marker of stress and health. Neuroscience $\mathcal{E}$ Biobehavioral Reviews, 36(2), 747-756. https://doi.org/10.1016/j.neubiorev.2011.11.009

Thayer, J. F., Hansen, A. L., Saus-Rose, E., \& Johnsen, B. H. (2009). Heart rate variability, prefrontal neural function, and cognitive performance: The neurovisceral integration perspective on selfregulation, adaptation, and health. Annals of Behavioral Medicine, 37(2), 141-153. https://doi.org/10.1007/s12160-009-9101-z

Thayer, J. F., \& Lane, R. D. (2000). A model of neurovisceral integration in emotion regulation and dysregulation. Journal of Affective Disorders, 61(3), 201-216. https://doi.org/10.1016/s01650327(00)00338-4

Thayer, J. F., \& Lane, R. D. (2009). Claude Bernard and the heart-brain connection: Further elaboration of a model of neurovisceral integration. Neuroscience $\mathcal{E}$ Biobehavioral Reviews, 33(2), 81-88. https://doi.org/10.1016/j.neubiorev.2008.08.004

Thayer, J. F., \& Sternberg, E. M. (2010). Neural aspects of immunomodulation: Focus on the vagus nerve. Brain, Behavior, and Immunity, 24(8), 1223-1228. https://doi.org/10.1016/j.bbi.2010.07.247

Thompson, R. A. (1994). Emotion regulation: A theme in search of definition. Monographs of the Society for Research in Child Development, 59(2-3), 25-52. https://doi.org/10.1111/j.1540-5834.1994.tb01276.x

Troy, A. S., \& Mauss, I. B. (2011). Resilience in the face of stress: Emotion regulation as a protective factor. In S. M. Southwick, B. T. Litz, D. Charney, \& M. Friedman (Eds.), Resilience and mental health: Challenges across the lifespan (pp. 30-44). New York, NY: Cambridge University Press. https://doi.org/10.1017/cbo9780511994791.004

Tugade, M. M., \& Fredrickson, B. L. (2007). Regulation of positive emotions: Emotion regulation strategies that promote resilience. Journal of Happiness Studies, 8(3), 311-333. https://doi.org/10.1007/s10902-006-9015-4

Vella-Brodrick, D. A., Rickard, N. S., \& Chin, T. C. (2014). An evaluation of positive education at Geelong Grammar School: A snapshot of 2013. Melbourne, Australia: The University of Melbourne.

Visted, E., Sørensen, L., Osnes, B., Svendsen, J. L., Binder, P. E., \& Schanche, E. (2017). The association between self-reported difficulties in emotion regulation and heart rate variability: The salient 
role of not accepting negative emotions. Frontiers in Psychology, 8, 1-9. https://doi.org/10.3389/fpsyg.2017.00328

Walker, F. R., Pfingst, K., Carnevali, L., Sgoifo, A., \& Nalivaiko, E. (2017). In the search for integrative biomarker of resilience to psychological stress. Neuroscience \& Biobehavioral Reviews, 74, 310-320. https://doi.org/10.1016/j.neubiorev.2016.05.003

Wang, Z., Lü, W., \& Qin, R. (2013). Respiratory sinus arrhythmia is associated with trait positive affect and positive emotional expressivity. Biological Psychology, 93(1), 190-196. https://doi.org/10.1016/j.biopsycho.2012.12.006

Westerhof, G. J., \& Keyes, C. L. M. (2010). Mental illness and mental health: The two continua model across the lifespan. Journal of Adult Development, 17, 110-119. https://doi.org/10.1007/s10804-0099082-y

Weytens, F., Luminet, O., Verhofstadt, L. L., \& Mikolajczak, M. (2014). An integrative theory-driven positive emotion regulation intervention. PLoS ONE, 9(4), e95677. https://doi.org/10.1371/journal.pone.0095677

Wielgus, M. D., Aldrich, J. T., Mezulis, A. H., \& Crowell, S. E. (2016). Respiratory sinus arrhythmia as a predictor of self-injurious thoughts and behaviors among adolescents. International Journal of Psychophysiology, 106, 127-134. https://doi.org/10.1016/j.ijpsycho.2016.05.005

Williams, D. P., Cash, C., Rankin, C., Bernardi, A., Koenig, J., \& Thayer, J. F. (2015). Resting heart rate variability predicts self-reported difficulties in emotion regulation: A focus on different facets of emotion regulation. Frontiers in Psychology, 6, 1-8. https://doi.org/10.3389/fpsyg.2015.00261

Yeung, D. Y., Ho, S. M., \& Mak, C. W. (2015). Brief report: Attention to positive information mediates the relationship between hope and psychosocial well-being of adolescents. Journal of Adolescence, 42, 98-102. https://doi.org/10.1016/j.adolescence.2015.04.004

Yeung, D. Y., Wong, C. K., \& Lok, D. P. (2011). Emotion regulation mediates age differences in emotions. Aging \& Mental Health, 15(3), 414-418. https://doi.org/10.1080/13607863.2010.536136

Zolkoski, S. M., \& Bullock, L. M. (2012). Resilience in children and youth: A review. Children and Youth Services Review, 34(12), 2295-2303. https://doi.org/10.1016/j.childyouth.2012.08.009 